\title{
Reward and nonreward odor cues: The role of the harderian gland
}

\author{
SUSAN M. NASH, BRENDA J. ANDERSON, TERESA L. REED, JOHN W. PARRISH, \\ and STEPHEN F. DAVIS \\ Emporia State University, Emporia, Kansas
}

\begin{abstract}
Through the comparison of the performance of a group of glandectomized rats with that of a group of sham-operated rats on a double-alternation schedule of reward-nonreward (R-N), the role of the harderian gland in the production and/or release of $R$ and $N$ odor cues was evaluated. The establishment of appropriate patterned responding by both harderianectomized and shamoperated animals argues against this gland's being involved in the odor control of maze learning. Additional potential odor sources are considered.
\end{abstract}

Subsequent to the proposal (Ludvigson \& Sytsma, 1967) and establishment (e.g., Davis, Prytula, Noble, \& Mollenhour, 1975; Davis, Whiteside, Bramlett, \& Petersen, 1981; Mellgren, Fouts, \& Martin, 1973; Prytula \& Davis, 1974, 1976; Seago, Ludvigson, \& Remley, 1970) of the premise that rats exude characteristic odors on reward (R) and nonreward $(\mathrm{N})$ occasions, several attempts have been made to isolate the anatomical source of such odor production. For example, McNeese and Ludvigson (1975) reported that the discriminable odor cue necessary for the development of appropriate double-alternation (DA) patterning was not produced/released by the preputial gland or the androgen-dependent accessory glands. Moreover, McNeese and Ludvigson (1975) indicated that such odors did not appear to be linked to urine production. More recently, Weaver, Whiteside, Janzen, Moore, and Davis (1982) reported a study in which the potential role of the footpad sweat gland in the production of $\mathrm{R}$ and $\mathrm{N}$ odors was evaluated. By spraying the feet of test subjects with aerosal plastic, this gland was functionally inactivated. The results indicated that precluding odors emanating from the feet significantly accentuated $R$ versus $N$ DA patterning, rather than decreasing it as would be predicted if a source of $\mathbf{R}$ or $\mathbf{N}$ odors had been eliminated.

On the other hand, Thiessen (1984) reported that lipids and pigments that are released from the harderian gland are involved in the determination and/or elicitation of social behavior in the Mongolian gerbil (Meriones unguiculatus). More directly to the question at hand, it has been shown that harderian material may serve as an attractant pheromone (Thiessen, 1984). The relatively large size of the harderian gland and the fact that it secretes a substantial amount of material suggest that it might be a possible location for the production and/or release of odor cues controlling maze performances, as described above. The present experiment was designed to investigate this possibility. Utilizing the technique of running one large

Requests for reprints should be directed to S. F. Davis, Department of Psychology, Emporia State University, Emporia, KS 66801. squad of animals composed of separate groups (see Prytula, Davis, \& Fanning, 1981) leads to several predictions. First, if a group of harderianectomized animals preceded a group of sham-operated controls, minimal, if any, odorbased patterning would be expected on the part of the first several animals in the sham-operated group; this would be due to a disruption in the odor source emanating from the preceding (harderianectomized) animals. Furthermore, if removal of the harderian gland results in a diminution or elimination of odor cues, then patterning would not be observed in the harderianectomized animals. However, if the order of testing groups is reversed (i.e., sham subjects precede glandectomized animals), then one would expect patterning to be developed by the harderianectomized animals due to the presence of salient odor cues emitted by the sham subjects.

\section{METHOD}

\section{Subjects}

Ten 90-day-old male rats purchased from the Holtzman Company, Madison, Wisconsin served as subjects. The subjects were individually caged with free access to water during the experiment.

\section{Apparatus}

The experimental apparatus was a single straight runway $(13.96 \mathrm{~cm}$ wide $\times 12.69 \mathrm{~cm}$ high), divided into startbox $(30.48 \mathrm{~cm})$, run section $(91.44 \mathrm{~cm})$, and goalbox $(60.96 \mathrm{~cm})$. Plexiglas guillotine doors separated the startbox and goalbox from the run section. A microswitch located on the startbox door and three photoelectric beams located 30.48 , 60.96 , and $91.44 \mathrm{~cm}$, respectively, beyond the start door, selectively started and stopped three electronic digital timers (Lafayette Model 54030) to yield start, run, and goal latencies. Thus, the start measure extended from the start door to the first beam, and the run measure extended from the first beam to the second beam $(15.24 \mathrm{~cm}$ beyond the goal door). Hence, the goal measure encompassed the $30.48 \mathrm{~cm}$ located in the middle of the goalbox. A plastic receptical recessed into the end wall of the goalbox served as the goal cup.

The startbox was painted gray (Rust-Oleum 975), and the run and goal sections and guillotine doors were painted black (Rust-Oleum 7776). In order to facilitate cleaning and odor removal, all painted surfaces were covered with two coats of polyurethane finish (Defthane, Clear Satin No. 2). To prevent odor dissipation, the apparatus was covered by $1 / 4$-in. Plexiglas lids which were, in turn, separated from the lip of the runway by a strip of V-Seal weather stripping. 


\section{Procedure}

Two weeks prior to pretraining, two equal-sized groups $(N=5)$ were randomly formed. At that time, the animals to be harderianectomized (Group $\mathrm{H}$ ) underwent the following surgical procedures for the bilateral removal of the harderian gland. Each subject was anesthetized via a $3 \mathrm{cc} / \mathrm{kg}$ intraperitoneal injection of Chloropent (Fort Dodge Industries). Harderianectomy was accomplished by lifting and snipping the nictitating membrane, and then locating and extracting the gland with a forceps. Surgical procedures for the sham-operated subjects (Group S) involved anesthetization and lifting (but not cutting) the nictitating membrane with a forceps.

All subjects were allowed a 2-week period for recovery from surgery. At the completion of the recovery period, a 2-week pretraining period was initiated by placing all subjects on a food-deprivation regimen designed to maintain each animal at $85 \%$ of its free-feeding body weight. The final 5 days of pretraining consisted of handling and taming (Days 1-2), habituation to the 45-mg BioServe Precision Reward Pellets in the home cage (Days 1-5), and an individual 5-min exploration in the baited apparatus (Days 4-5).

Experimental testing immediately followed pretraining and was divided into two phases. During both phases, all subjects received 8 daily trials in a DA sequence (RRNNRRNN). On each trial, the designated subject was removed from the home cage and placed into the startbox. Following a 3-sec confinement, the start door was raised, and the subject was allowed to traverse the runway. On $\mathbf{R}$ trials, subjects remained in the goalbox until all pellets were consumed, or until $20 \mathrm{sec}$ had elapsed if the pellets had been eaten already. On $\mathrm{N}$ trials, subjects were confined to the empty goalbox for $20 \mathrm{sec}$.

At the start of Phase 1, the subjects were assigned a permanent runningorder number (1-5) within their respective groups and were run in this order on all days of training. Groups $\mathrm{H}$ and $\mathrm{S}$ were run as one large squad during both phases. On all days, Trial 1 was administered to all subjects before Trial 2 , and so forth. As the runway was swabbed with a water-dampened sponge and allowed to air dry for $5 \mathrm{~min}$ at the completion of each trial by all subjects, the initial subject to be tested always ran in a clean, odor-free apparatus. During Phase 1 (13 days, 104 trials), Group H preceded Group S on all days; during Phase 2 ( 5 days, 40 trials), Group $S$ preceded Group $\mathrm{H}$ on all days.

\section{RESULTS AND DISCUSSION}

All latencies were converted to speeds (meters per second) through reciprocation and multiplication by the appropriate metric constant. In turn, the speeds for the daily eight-trial DA sequence were combined as follows: the first two trials were averaged to yield an $R_{1}$ composite score, the next two trials were averaged to yield an $\mathrm{N}_{1}$ composite score, and so forth. Hence, the daily DA performance of each subject was reduced to four scores, which were used for graphing and analysis. As significant DA effects were shown only in the goal measure, only those results will be presented.

Mean goal speeds for the first animal in the harderian running order (top) and the first animal in the sham running order (bottom) for the last 4 days of Phase 1 and the 5 days of Phase 2 are shown in Figure 1. As would be predicted by odor theory, when the harderianectomized animals preceded the shams (Phase 1), patterned responding was not shown by the initial harderian subject who was always tested in a clean, odor-free runway. However, attributing a role in the production of $\mathrm{R}$ or $\mathrm{N}$ odors to the harderian gland is seriously questioned by the Phase 1 performance of the initial sham subject. This animal should have shown no, or at best minimal, patterning if the odor output of the preceding harderian animals had

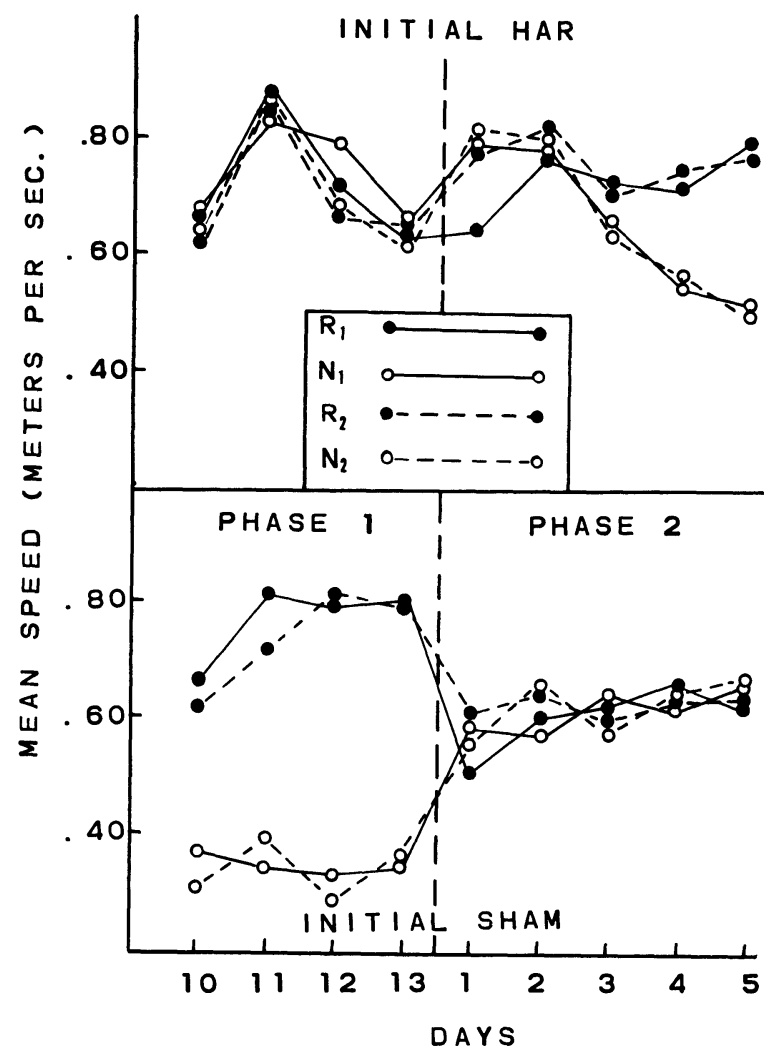

Figure 1. Mean goal speeds (meters per seconds) of the initial harderianectomized animal (top) and the initial sham-operated animal (bottom) during Phase 1 (Group $\mathbf{H}$ preceded Group S) and Phase 2 (Group S preceded Group H).

been significantly reduced. Clearly, this was not the case. Reversing the group ordering during Phase 2 resulted in the development of patterning by the initial harderian animal and the immediate elimination of patterning by the first sham animal (see Figure 1, right panel). As with the Phase 1 data, these results are predictable because: (1) the first sham animal was tested in an odor-free apparatus during Phase 2, and (2) the first harderian animal had the accumulated odors from the preceding sham animals upon which to base its performance. The performance of the first harderian animal also provides clear verification that removal of the harderian gland did not damage the olfactory system.

Concerning the performance of the remaining harderian animals, goal speeds for the last 4 days of Phase 1 and Phase 2 for the first 2 animals to follow the initial subject and the last 2 animals in the group are shown in Figure 2. Clearly, the first 2 animals did not pattern during Phase 1, but patterning was developed on the last 2 days of this phase by the last 2 animals. Analysis of variance incorporating one between-subjects factor, subjects (first 2 vs. last 2), and two within-subjects factors, type of trial $\left(R_{1}, N_{1}, R_{2}, N_{2}\right)$ and days, was performed on these data and yielded significance for the type of trial $\times$ days interaction $[F(9,18)=2.79, p<.05]$. Newman-Keuls tests indicated that the $\mathrm{N}_{1}$ and $\mathrm{N}_{2}$ speeds of the last 2 harderian animals were significantly $(p<.05)$ slower 
than their $\mathbf{R}_{1}$ and $\mathbf{R}_{2}$ speeds and all speeds of the first 2 harderian subjects. Thus, it is clear that appropriate Phase 1 patterning had been established by the last 2 animals in this group. If the harderian gland were a major determinant of odor production, such results would not have been anticipated. Turning to Phase 2 , it is clear from Figure 2 (right panel) that rotating Group $\mathrm{H}$ now to follow the sham subjects results in the establishment of patterning by the first 2 harderian animals. Analysis of variance yielded significance for the subjects $\times$ type of trial $\times$ days interaction $[F(12,24)=2.59, p<.05]$. Newman-Keuls tests indicated that $R_{1}$ and $R_{2}$ speeds of the last 2 harderians were significantly $(p<.05)$ faster than their $N_{1}$ and $N_{2}$ speeds on all days of Phase 2 . Additionally, the $\mathbf{R}_{\mathbf{1}}$ and $\mathbf{R}_{\mathbf{2}}$ speeds of the first 2 harderians were found to be significantly $(p<.05)$ faster than their own $\mathrm{N}_{1}$ and $\mathrm{N}_{2}$ speeds on Days 3-5. Furthermore, all speeds of the first 2 harderians were significantly $(p<.05)$ faster than the $\mathrm{N}_{1}$ and $\mathrm{N}_{2}$ speeds of the last 2 harderians.

Mean goal speeds of the first 2 sham animals to follow the first animal in Group $S$ and the last 2 animals in that group are shown in Figure 3. In agreement with an odor accumulation explanation, appropriate DA patterning had been established by the last 4 days of Phase 1 by both sets of animals. In support, only the type of trial factor was

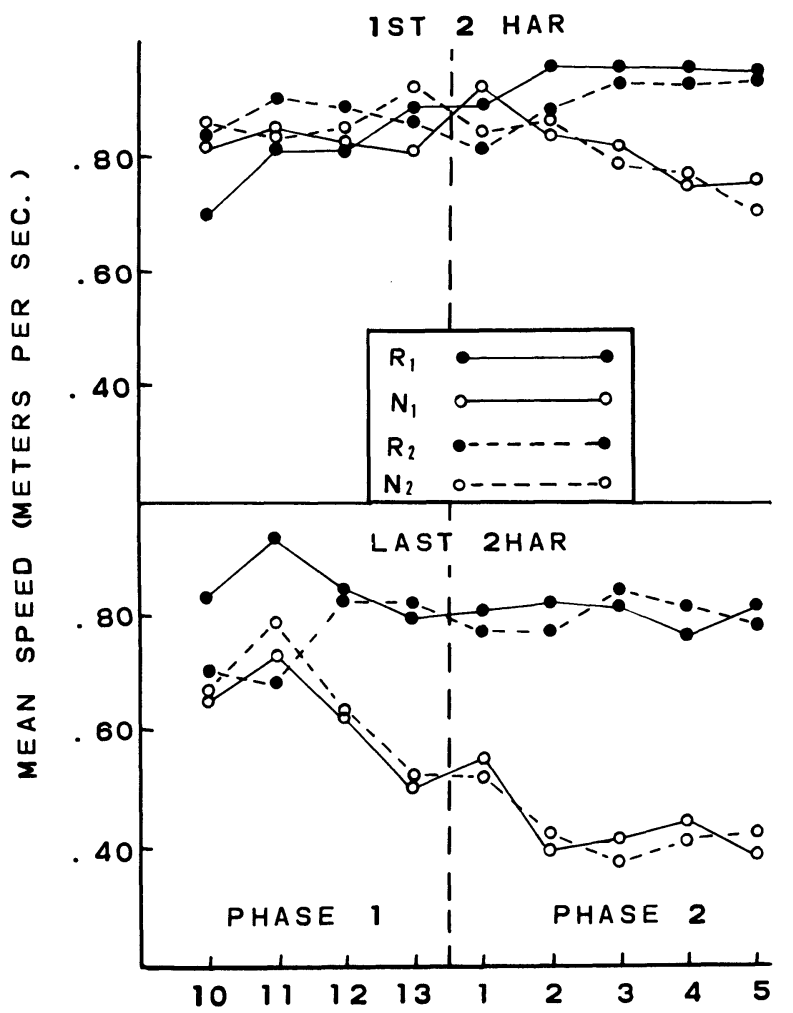

DAYS

Figure 2. Mean goal speeds (meters per second) of the first 2 harderianectomized animals that followed the initial animal in Group $\mathbf{H}$ (top) and the last 2 animals in the Group $\mathbf{H}$ running order (bottom) during Phases 1 and 2.

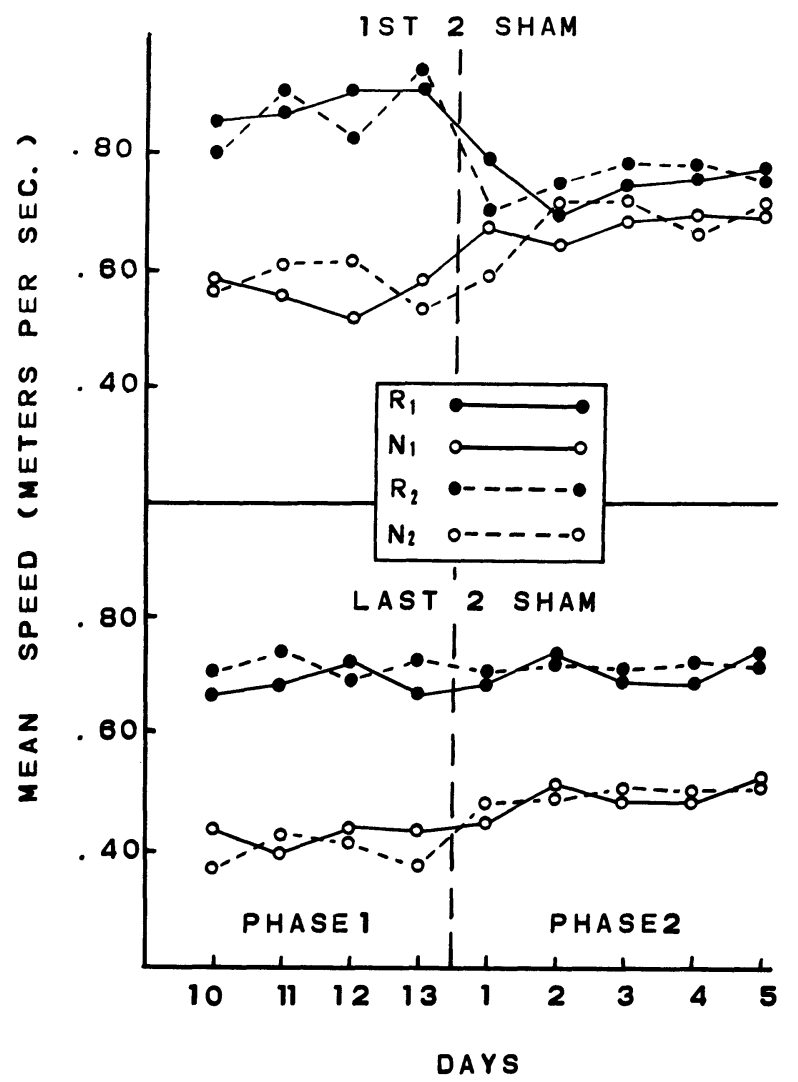

Figure 3. Mean goal speeds (meters per second) of the first 2 shamoperated animals that followed the initial animal in Group $S$ (top) and the last 2 animals in the Group $S$ running order (bottom) during Phases 1 and 2.

found to be statistically reliable $[F(3,6)=13.36, p<$ .01]. Subsequent Newman-Keuls tests indicated that $R_{1}$ and $\mathbf{R}_{2}$ speeds did not differ but were significantly $(p<.01)$ faster than the $\mathrm{N}_{1}$ and $\mathrm{N}_{2}$ speeds, which did not differ. Analysis of the Phase 2 speeds of these animals yielded significance for the groups $\times$ type of trial interaction $[F(3,6)=5.82, p<.05]$. Newman-Keuls tests indicated that $R_{1}$ and $R_{2}$ speeds of the last 2 shams were significantly $(p<.05)$ faster than their $\mathrm{N}_{1}$ and $\mathrm{N}_{2}$ speeds. These results corroborate the graphical impression of Figure 3 that rotating the groups resulted in the cessation of patterning in the initial sham animals during Phase 2 (also see Figure 1).

Taken collectively, these results argue, rather convincingly, that the harderian gland is not involved in the production and/or release of $\mathrm{R}$ or $\mathrm{N}$ odor cues. As noted, the present experiment provides several lines of supportive data. First, if this gland were involved, then the development of strong patterned responding by the last 2 animals in Group $\mathrm{H}$ during Phase 1 would not have been expected. Second, if odor production had been disrupted by the glandectomy, then the initial sham animal should not have displayed strong Phase 1 patterned responding. Third, if removal of the harderian gland interferes with the production of odor cues, then the pat- 
terned performance of the last 2 animals in Group $\mathrm{H}$ during Phase 2 should have been weaker than that of the first 2 Group $\mathrm{H}$ animals due to the dissipation of effective odor cues with the running of additional non-odor-producing harderianectomized animals. As these effects were not shown, the present data are better explained by an odoraccumulation view (see Prytula et al., 1981), which suggests that $\mathbf{R}$ and $\mathbf{N}$ odors accumulate as a function of the number of subjects tested.

The lack of involvement of the harderian gland in the production of $\mathrm{R}$ and $\mathrm{N}$ odors suggests that other potential odor sources will need to be evaluated. There are several viable possibilities. For example, one might want to consider "multilocular adipose tissue" or the hibernating gland. According to Green (1955), this interesting gland "modifies the action of toxins, adrenalin, chloroform, tetanus toxin and cobra venom, retarding the action of some, accelerating others"' (p. 87). Likewise, the parotid gland might be viewed as a potential odor source. If this proves to be the case, then salivary and breath-related factors also will need to be evaluated. Alternatively, the system may result from complex interactions of two or more secretory organs.

\section{REFERENCES}

Davis, S. F., Prytula, R. E., Noble, M. J., \& Mollenhour, M. N. (1976). Motivational specificity of the signal value of odor cues. Animal Learning \& Behavior, 4, 407-410.

Davis, S. F., Whiteside, D. A., Bramlett, J. A., \& Petersen, S. H. (1981). Odor production and utilization under conditions of nonreward and small reward. Learning \& Motivation, 12, 364-382.

GreEN, E. C. (1955). Anatomy of the rat. New York: Hafner.

Ludvigson, H. W., \& Sytsma, D. (1967). The sweet smell of success: Apparent double-alternation in the rat. Psychonomic Science, 9, 283-284.
MCNeESE, R., \& Ludvigson, H. W. (1975, April). Searching for the source of frustration odor. Paper presented at the annual meeting of the Southwestern Psychological Association, Houston, TX.

Mellgren, R. L., Fouts, R. S., \& Martin, J. W. (1973). Approach and escape to conspecific odors of reward and nonreward in rats. Animal Learning \& Behavior, 1, 129-132.

Prytula, R. E., \& DAvis, S. F. (1974). Runway performance as a function of positively and negatively correlated olfactory cues. Psychological Reports, 35, 735-740.

Prytula, R. E., \& Davis, S. F. (1976). The relationship between locus of odor cues and double-alternation responding in the rat. Animal Learning \& Behavior, 4, 352-356.

Prytula, R. E., Davis, S. F., \& Fanning, J. J. (1981). Acquisition of a running response as a function of odor buildup, squad rotation, and introduction of naive subjects. Animal Learning \& Behavior, 9 , 556-560.

Seago, J. D., Ludvigson, H. W., \& Remley, N. R. (1970). Effects of anosmia on apparent double-alternation in the rat. Journal of Comparative \& Physiological Psychology, 71, 435-442.

THIESSEN, D. D. (1984, MARCH). The harderian gland in communication and thermoregulation. Paper presented at the annual meeting of the Southwestern Comparative Psychology Association, Lubbock, TX.

Weaver, M. S., Whiteside, D. A., Janzen, W. C., Moore, S. A., \& DAvIs, S. F. (1982). A preliminary investigation into the source of odor-cue production. Bulletin of the Psychonomic Society, 19, 284-286.

\section{NOTE}

1. Obviously, there may be separate anatomical locations for the production/release of $\mathrm{R}$ and $\mathrm{N}$ odors. Furthermore, even though it might be argued that removal of the harderian gland (and potential $R$ odor cues) would leave the animal with an $\mathrm{N}$ odor versus no odor discrimination upon which to develop appropriate alternation, a noticeable collapse in the $\mathbf{R}$ versus $\mathbf{N}$ differential would still be anticipated. This prediction is based upon the demonstrated attractive properties of $\mathrm{R}$ odors (e.g., Mellgram, Fouts, \& Martin, 1973).

(Manuscript received for publication October 31, 1985.) 